\title{
PROFISSIONAIS DE NÍVEL TÉCNICO EM FARMÁCIA: DISCUTINDO A EDUCAÇÃO FORMAL PARA INSERÇÃO E PARTICIPAÇÃO
}

\section{Sebastião Gonçalves de Barros Neto ${ }^{1}$}

\author{
Alexandre Jacob ${ }^{2}$ \\ Recebido em: fevereiro/2020 \\ Publicado em: abril/2020
}

RESUMO: A pesquisa propõe-se revisar a literatura que trata dos Técnicos em Farmácia, egressos dos Cursos Técnicos de Nível Médio em Farmácia, pois, ao passo que se reconhece a Farmácia como promotora de saúde, entende-se que seus recursos humanos devem possuir educação formal específica, regulamentação ocupacional e profissional, registro e exercício profissional fiscalizado por órgão competente. Ao debruçarmos sobre a literatura que versa sobre os profissionais de nível Técnico em Farmácia foi possível descrever, conhecer e problematizar o contexto da formação Técnica em Farmácia no Brasil e propor novos caminhos para a área Técnica em Farmácia Brasileira, em especial para a Educação Profissional e Tecnológica em Saúde.

Palavras-chave: Técnico em Farmácia; Educação Profissional em Saúde; Políticas Públicas; Assistência Farmacêutica.

\footnotetext{
${ }^{1}$ Instituto Federal do Espírito Santo, Campus Colatina, ES. E-mail: sebastiaogbarros@ outlook.com ${ }^{2}$ Instituto Federal do Espírito Santo, Campus Colatina, ES. E-mail: alexandre.jacob10@gmail.com
} 


\title{
PROFESSIONALS OF TECHNICAL LEVEL IN PHARMACY: DISCUSSING FORMAL EDUCATION FOR INSERTION AND PARTICIPATION
}

\begin{abstract}
The research proposes to review the literature that deals with the pharmacy technicians, graduates of technical courses of vocational schooling in Pharmacy. While recognizing this area as a promoter of health, it is understood that these professionals must have specific formal education, occupational and professional regulation, registration and professional exercise supervised by a competent body. When we look at the literature that deals with technical level professionals in Pharmacy, it was possible to describe, know and problematize the context of their formation in Brazil and to propose new paths for the technical area in Brazilian Pharmacy, especially for professional and technological education in healthcare.
\end{abstract}

Key words: Pharmacy Technician; Professional Education in Health; Public Policies; Pharmaceutical Assistance.

\section{INTRODUÇÃO}

Desde sua instituição, sobretudo no último decênio, a Rede Federal de Educação Profissional, Científica e Tecnológica, tem se expandido por intermédio da criação de novos Institutos Federais de Educação, Ciência e Tecnologia (IF), tendência também observada na esfera da educação privada; por conseguinte, novos cursos técnicos de nível médio e superior, bem como os de pós-graduação lato e stricto sensu foram criados. Em meio a esse contexto de expansão, originaram-se cursos que diplomam e conferem o grau de Técnico de Nível Médio em Farmácia em diferentes instituições públicas e privadas de ensino, conjuntura que possivelmente, a longo prazo, colocará um fim na ausência de indivíduos atuando sem a devida qualificação requerida teoricamente pelo segmento farmacêutico, tornando obsoleto o profissional sem educação formal — auxiliar de Farmácia, balconista e o "prático". No Brasil, diferentemente de outros países, grande parte dos serviços e das atividades de saúde não privativas do Farmacêutico são realizados por leigos: auxiliares de farmácia, balconistas 
e "práticos" (NAVES; MERCHAN-HAMANN; SILVER, 2005; BEZZEGH; GOLDENBERG, 2011; CORRER; OTUKI, 2013).

O Ministério da Educação, por meio do Catálogo Nacional de Cursos Técnicos, reconheceu o Curso de Nível Médio em Técnico em Farmácia. No entanto, a Lei ${ }^{\circ}$ 3.820, de 11 de novembro de 1960, e a Lei $n^{\circ}$ 5.991, de 17 de dezembro de 1973, não preveem a incorporação desse profissional - inscrição de quadros separados com a denominação "Técnico em Farmácia” nos Conselhos Regionais de Farmácia. Portanto, os concluintes dos cursos de formação e habilitação Técnica em Farmácia acabam por atuar no mercado sob a supervisão do Farmacêutico sem o registro (BRASIL, 1960; PEREIRA, 2009; CORRAL; SOUZA; NEGRÃO, 2009; CORRER; PONTAROLO; RIBEIRO, 2013).

A inexistência de uma legislação específica que regulamente e exija a formação técnica em Farmácia para atuar no segmento do mercado farmacêutico repercute de modo negativo na oferta e na demanda de cursos profissionalizantes de Técnico em Farmácia. Portanto, poucos possuem formação compatível com o cargo ou função (por não existir uma exigência); em geral, possuem baixa escolaridade, pouca ou nenhuma formação específica na área (CORRER; PONTAROLO; RIBEIRO, 2013, BARROS NETO; CYSMEIROS; BORGES, 2018).

A atenção primaria é a principal área de trabalho Farmacêutico e Técnico em Farmácia no Brasil (CORRER; OTUKI, 2013). Tanto no serviço privado quanto no serviço público, suas atividades correspondem às ações do processo de trabalho dos diversos segmentos da área farmacêutica. O conjunto dessas atividades, no plano institucional ou na sociedade, são identificados como serviços. Os serviços técnicogerenciais, que incluem a programação, a solicitação, o armazenamento e o descarte de produtos farmacêuticos, são de natureza técnica especifica, da mesma forma que os serviços técnicos assistenciais farmacêuticos (dispensação, orientação, consulta, revisão da farmacoterapia, conciliação terapêutica, seguimento farmacoterapêutico, ações de educação em saúde e suporte técnico para a equipe de saúde) (BRASIL, 2009b; CONSELHO FEDERAL DE FARMÁCIA, 2013). 
Na Prática Farmacêutica e Técnica em farmácia comunitária, as atividades se dividem entre gerenciais e administrativas, assistenciais e clínicas. Nas atividades assistenciais e clínicas, os Técnicos em Farmácia auxiliam o Farmacêutico na documentação do Cuidado Farmacêutico, cooperando para a oferta do gerenciamento integral da farmacoterapia prescrita (MELO et al., 2017).

As instituições formadoras, ao educar para o exercício Farmacêutico, conferindo o grau de bacharel em Farmácia, além de subsídios teóricos, técnicos e intelectuais, objetivam também a formação de indivíduos emancipados, críticos e reflexivos. Portanto, tem se buscado pautar o ensino no princípio da integralidade omnilateralidade —, objetivando a formação humana de maneira oposta à formação unilateral que advém do trabalho alienado, produto das inter-relações entre a divisão do trabalho, a reificação e as relações burguesas. Destarte, deve ser considerada a totalidade, compreendendo de modo integral as relações sociais e políticas. Consequentemente, há um esforço de ofertar uma proposta de educação ampliada, transformadora, critica e libertadora que, entre outras coisas, conceba o homem como ser integrado às forças sociais e de forma alguma como subserviente às forças produtivas. Dessa forma, os profissionais Farmacêuticos formados com essa visão deveriam ter um posicionamento diferente no que se refere à qualificação e ao reconhecimento profissional dos Técnicos em Farmácia, uma vez que, ao nos debruçarmos sobre a literatura disponível, evidenciamos a complexidade do trabalho entre Técnicos em Farmácia e Farmacêuticos, visto que se encontram em um campo enredado de interesses, poder, disputas e resistências por parte dos Farmacêuticos e dos Conselhos de Farmácia (BARROS NETO; CYSNEIROS; BORGES, 2018).

Os Cursos Técnicos de Nível Médio em Farmácia estão fundamentados nos princípios norteadores da EPT. Desse modo, também visam a oferta de uma educação que forme na perspectiva da omnilateralidade, ao desenvolver habilidades e competências humanas; ao preparar cada indivíduo para o exercício pleno de suas funções e de conhecimentos adquiridos com discernimento e propositividade, para compreender e contextualizar a educação e o trabalho como fruto de uma produção social (MERHY, 2002; BARROS NETO, 2017) e para que sejam protagonistas de uma cogestão, no que se refere ao trabalho em equipe. 
Entendemos a farmácia comunitária no Brasil como sendo um recurso de grande importância para a saúde pública do país, sendo imprescindível que a equipe seja composta unicamente por profissionais Farmacêuticos e Técnicos em Farmácia devidamente formados. Estudos como este contribuem para o processo de formulação das políticas públicas, bem como para a formação de recursos humanos especializados.

Como já foi dito, a atuação do Técnico em Farmácia qualifica as ações em saúde, contribuindo para a garantia da integralidade das/nas ações, e, nesse sentido, a Prática Farmacêutica e Técnica na área deve ser transformada (STEPHANELLI, 2015; BARROS NETO; CYSNEIROS; BORGES, 2018).

Segundo os novos marcos legais, a farmácia não é mais entendida como puramente um ambiente de cunho comercial, mas é, para todos os efeitos legais, um Estabelecimento de Saúde (BRASIL, 2014). Portanto, parece-nos plausível sustentar a tese de que todos que ali estão deveriam minimante possuir educação formal — refirome à Formação Técnica de Nível Médio em Farmácia — para ofertar um cuidado em saúde adequado. No entanto, por não poderem se inscrever nos Conselhos de Farmácia em quadros separados como técnicos, diante da oferta do curso muitos desistem de ingressar e, aqueles que já atuam na área, acabam não se qualificando. Os poucos que iniciam o curso e o concluem comumente judicializam a questão. Portanto, entendemos que esforços devem ser empreendidos no sentido de modificar o entendimento da legislação vigente, considerando a lógica da saúde e do interesse público.

Como já foi dito, embora exista a oferta (mesmo que exígua), poucos demonstram interesse, pois a profissão de Técnico em Farmácia não possui recepção e direcionamento legal, visto que se encontra em um campo enredado de interesses, poder, disputas e resistências por parte dos profissionais Farmacêuticos e Conselhos de Farmácia.

Diferentemente dos concluintes dos cursos de bacharel em farmácia, os indivíduos que, diante da oferta, ingressam no Curso Técnico de Nível Médio em Farmácia, ao concluírem e receberem o grau não podem se inscrever nos CRF, porque a profissão ainda não foi legalmente reconhecida, embora conste no Catálogo Nacional de Cursos Técnicos, do Ministério da Educação (BRASIL, 2009a). O segmento 
farmacêutico, na prática, não exige educação formal e desconsidera a formação de nível técnico ao remunerar esses funcionários, sendo comum receberem valores iguais aos leigos (sem educação formal específica).

Considerando que a conjuntura possivelmente repercute sobre a demanda (interesse e busca pela qualificação), oferta (de cursos), inserção no mercado de trabalho e nas relações de trabalho, este estudo tem como objetivo se debruçar sobre a revisão da literatura que versa sobre os profissionais Técnicos de Nível Médio em Farmácia, com o intuito de identificar possíveis elementos - subsídios que possam contribuir para a EPT e para área Técnica em Farmácia, através da compreensão do contexto histórico e político que culminou na criação do curso de Técnico em Farmácia, considerando a expansão da EPT no Brasil como sendo o elemento desencadeador, bem como o contexto político do recepcionamento e do direcionamento legal da Prática Técnica em Farmácia, incluindo os conflitos, os interesses, as disputas e as resistências que enredam o campo.

\section{DESENVOLVIMENTO}

DO AUXILIAR/APRENDIZ AO TÉCNICO EM FARMÁCIA: O CAMINHO DAS ARTES FARMACÊUTICAS NA HISTÓRIA DO BRASIL

Ao atentarmos para os caminhos percorridos pelas artes farmacêuticas no Brasil no decurso da história, é possível compreender e apontar, em certa medida, as possíveis conjunturas que culminaram na divisão do trabalho na área da farmácia sob a égide do grau de formação (STEPHANELLI, 2015).

Logo nos primeiros anos do século XIX no Brasil, o que hoje conhecemos por farmacêutico recebia o nome de boticário; do mesmo modo, as farmácias eram conhecidas como boticas. Nas boticas, os medicamentos eram produzidos/manipulados artesanalmente e comercializados conforme a demanda. Nesse período, a relação entre cliente/paciente e boticário/farmacêutico era profícua e adornada por um forte vínculo de amizade e confiança, parte disso fruto de um contexto em que o país não dispunha de tantas boticas/farmácias, sendo comum a existência de apenas um estabelecimento farmacêutico por cidade (STEPHANELLI, 2015). 
As artes farmacêuticas, aqui entendidas como sendo as técnicas e os conhecimentos referentes às atividades e aos serviços desenvolvidos no âmbito das boticas/farmácias, eram repassadas — transmitidas pelo "mestre" aos demais "aprendizes" - aos auxiliares/funcionários que se interessavam em aprendê-las para praticá-las, pois ainda não havia, no país, instituições formadoras para o ofício em Farmácia, situação que forçava o governo a conceder permissão para abertura de boticas a leigos, tempo também marcado pela inexistência de fiscalizações regulares e procedimentos farmacopeicos padronizados (SANTOS, 1999; VELLOSO, 2007).

Ainda no período que compreende o Brasil Colônia (1530 a 1822), de modo assistemático e tímido deu se início à “formação" (dos) boticária (os), mas ainda, como supramencionado, aprendia-se nas próprias boticas com aqueles que detinham certa experiência na área. No entanto, após esse processo de imersão, devia-se realizar os exames aplicados pela Fiscatura-mor ${ }^{3}$ para comprovar as habilidades e as competências requeridas sobre a Pharmacopêa Geral para o Reino e Domínios de Portugal (STEPHANELLI, 2015). Havendo aprovação no exame, o postulante deveria comprovar o exercício prático de, no mínimo, quatro anos em uma botica de responsabilidade de um boticário legalizado pelo mesmo trâmite regulamentar. Satisfazendo tais requisitos, o delegado da Fiscatura-mor conferia ao requerente o título régio da Carta de Farmácia do Boticário (EDLER, 2006; VELLOSO, 2007).

No início do segundo vintênio do século XIX, extinguiu-se a Fiscatura-mor e a Câmara Municipal foi revestida de autoridade para proceder com as inspeções públicas sanitárias, por intermédio de seus inspetores de saúde que, no caso especial das boticas, aferiam e examinavam a qualidade e o estado das drogas; a organização e a higiene; os preços aplicados (EDLER, 2006; VELLOSO, 2007).

Ainda nesse período, a Carta Régia, publicada em 3 de outubro de 1832 por Dom Pedro II, determinou a "Reforma do Ensino Médico", o que finalmente permitiu a criação e a incorporação do curso de Farmácia em duas Faculdades de Medicina, sediadas nas cidades da Bahia e do Rio de Janeiro. Logo, para obter o título de

\footnotetext{
${ }^{3}$ [...] era o órgão responsável pela fiscalização do exercício das artes de curar e pela concessão de cartas de físicos, boticários, médicos práticos e curandeiros do Reino, sendo representado pelos cargos de Físico-mor, escrivão-secretário, juízes-comissários-delegados, escrivão, meirinho e visitadorexaminadores da arte farmacêutica (VELLOSO, 2007, p. 26).
} 
pharmaceutico, o postulante deveria cursar e ser aprovado (em um período de três anos) nas disciplinas do curso superior de Pharmacia e, concomitantemente ou não, ter três anos de prática em uma botica/pharmacia de um boticário legalizado (BRASIL, 1832).

Pouco depois, em 1839, foi criada, na cidade mineira de Ouro Preto, a primeira Faculdade de Farmácia do Brasil, independente do curso de Medicina. Nos anos seguintes, com a criação de entidades de classe ${ }^{4}$, iniciou-se uma maior preocupação em torno da melhoria da qualidade do ensino "pharmaceutico" e do combate ao exercício ilegal da profissão (VELLOSO, 2007).

A demora em torno da institucionalização e regulamentação da profissão "pharmaceutica" e da expansão do ensino "pharmaceutico" no país cooperou para o funcionamento de inúmeras boticas sem a presença desse profissional (VELLOSO, 2007; STEPHANELLI, 2015).

Os anos em que a farmácia brasileira ficou entregue unicamente a indivíduos sem a devida educação formal descontruiu a identidade do Farmacêutico. Muitos "não farmacêuticos" - auxiliares e proprietários - articularam-se e conseguiram autorizações para exercerem a responsabilidade técnica dos estabelecimentos. Os anos passaram e proprietários começaram a ser denominados práticos em Farmácia, oficiais em Farmácia e provisionados em Farmácia, conjuntura que enredou de fronteiras divisões — às atividades laborais em Farmácia, gerando muita insatisfação por parte dos Farmacêuticos. Todo esse descontentamento resultou na criação do Conselho Federal de Farmácia (CFF), por força da Lei $n^{\circ} 3.820$, de 11 de novembro de 1960 (BRASIL, 1960; STEPHANELLI, 2015).

Art. $1^{\circ}$ - Ficam criados os Conselhos Federal e Regionais de Farmácia, dotados de personalidade jurídica de direito público, autonomia administrativa e financeira, destinados a zelar pela fiel observância dos princípios da ética e da disciplina da classe dos que exercem atividades profissionais farmacêuticas no País (BRASIL, 1960).

\footnotetext{
4 Sociedade Farmacêutica Brasileira (1851) e o Instituto Farmacêutico do Rio de Janeiro (1858) (VELLOSO, 2007).
} 
Ao restabelecer, em seu Art. $33^{5}$, critérios para o processo de licenciamento de oficiais e práticos, essa peça legal forçou o fim da possibilidade de indivíduos, sem a devida educação formal, tornarem-se responsáveis técnicos (BRASIL, 1960).

Já a inscrição em quadros distintos para os auxiliares que possuíam formação técnica - educação formal técnica de nível médio - é facultada, conforme o que está expresso no art. 14, parágrafo único, apenas para

[...] a) os profissionais que, embora não farmacêuticos, exerçam sua atividade (quando a lei autorize) como responsáveis ou auxiliares técnicos de laboratórios industriais farmacêuticos, laboratórios de análises clínicas e laboratórios de controle e pesquisas relativas a alimentos, drogas, tóxicos e medicamentos; b) os práticos ou oficiais de Farmácia licenciados (BRASIL, 1960).

Portanto, diante da redação do art. 14, os Técnicos em Farmácia, mesmo possuindo educação formal, não detêm o direito de inscrição como profissional de nível de formação distinta do Farmacêutico (BRASIL, 1960; STEPHANELLI, 2015).

Pouco depois, com o "Movimento de 1964" e a ascensão dos militares ao poder, o Brasil vivenciava um período de marcantes mudanças em seu modelo econômico fruto do "milagre econômico" —, decorrentes do alavancado processo de industrialização. Com a produção em larga escala de medicamentos pela indústria farmacêutica brasileira, o mercado demandava a fortiori mão de obra qualificada (BRASIL, 1970; STEPHANELLI, 2015).

Ciente disso, o presidente da República Emílio Garrastazu Médici sancionou a "Reforma do Ensino de $1^{\circ}$ e $2^{\circ}$ graus" por intermédio da Lei de Diretrizes e Bases da Educação Nacional (Lei $n^{\circ}$ 5.692), de 1971, que instituiu o ensino profissionalizante obrigatório nas instituições públicas de ensino.

\footnotetext{
${ }^{5}$ [...] oficiais de Farmácia, já habilitados na forma da lei, poderão ser provisionados para assumirem a responsabilidade técnico-profissional para farmácia de sua propriedade, desde que, na data da vigência desta lei, os respectivos certificados de habilitação tenham sido expedidos há mais de 6 (seis) anos pelo Serviço Nacional de Fiscalização da Medicina ou pelas repartições sanitárias competentes dos Estados e Territórios, e sua condição de proprietários de farmácia datada de mais de 10 (dez) anos, sendo-lhes, porém, vedado o exercício das mais atividades privativas da profissão de farmacêutico (BRASIL, 1960).
} 
Destarte, ao viabilizar o processo de escolarização e a criação sistematizada dos cursos técnicos de nível médio, contribuiu para a criação de inúmeros cursos técnicos de nível médio em saúde, entre os quais o Curso de Nível Médio em Técnico em Farmácia.

Neste contexto, no que diz respeito ao Curso Técnico de Farmácia, o período de formação demandava quatro anos, contemplando ainda a obrigatoriedade de 500 horas de estágio supervisionado em estabelecimentos farmacêuticos. O curso oferecia uma habilitação parcial em Auxiliar de Farmácia e, ao concluírem com aprovação o terceiro ano, os alunos recebiam o certificado de conclusão do $2^{\circ}$ grau. Porém, para receber o diploma de Técnico de Farmácia, era indispensável conclusão do quarto ano (STEPHANELLI, 2015, p. 66).

Ainda nos anos de chumbo do "Movimento de 1964", o embalo do contexto brasileiro de expansão industrial também culminou na elaboração da Lei no 5.991 que foi sancionada no dia 17 de dezembro de 1973 pelo mesmo presidente. A Lei em questão definiu as atividades e os estabelecimentos farmacêuticos como comércio e deu outras providências. Embora tenha sido a primeira legislação sanitária brasileira direcionada ao comércio de medicamentos, devemos ter a clareza de reconhecer o seu caráter autoritário e mercantilista, ao passo que define os estabelecimentos farmacêuticos como comércios voltados unicamente ao lucro, bem como também possibilita a abertura por leigos $^{6}$ desde que cumpridas as exigências quanto à responsabilidade técnica. No entanto, convenhamos que, em 1970, existiam poucos cursos de Farmácia no Brasil (BRASIL, 1973; BARROS NETO, 2017).

Além disso, mal redigida ao utilizar o termo "técnico responsável"7, essa legislação não é suficientemente clara quanto à obrigatoriedade do profissional Farmacêutico (bacharel em farmácia inscrito no CRF) como o único elegível à responsabilidade técnica nos estabelecimentos farmacêuticos, vício que dá margem para decisões jurídicas ineptas desfavoráveis quanto a essa imprescindibilidade (BRASIL, 1973; CORRER; OTUKI, 2013).

\footnotetext{
${ }^{6}$ Art. 57 - Os práticos e oficiais de farmácia, habilitados na forma da lei, que estiverem em plena atividade e provarem manter a propriedade ou co-propriedade de farmácia em 11 de novembro de 1960, serão provisionados pelo Conselho Federal e Conselhos Regionais de Farmácia para assumir a responsabilidade técnica do estabelecimento (BRASIL, 1973).

${ }^{7}$ Art. 15 - A farmácia e a drogaria terão, obrigatoriamente, a assistência de técnico responsável, inscrito no Conselho Regional de Farmácia, na forma da lei.
} 
Portanto, por permitir uma interpretação equivocada (quando lida ao pé da letra), a lei em questão caminhou na contramão do que se pretendia com a "Reforma do Ensino de $1^{\circ}$ e $2^{\circ}$ graus", porque impulsionou uma nova onda de indivíduos sem educação formal, acrescida também por técnicos, a reivindicarem para si a responsabilidade técnica, uma vez que existia uma provável dificuldade enfrentada pelos proprietários para encontrar farmacêuticos formados que atendessem às exigências da Lei $n^{\circ} 3.820 / 60$, pois o número de faculdades que ofertavam o curso de Farmácia era exíguo naquele período (STEPHANELLI, 2015).

O imbróglio culminou em inúmeras ações judiciais. No entanto, até o momento (fev. 2019), todas as ações movidas foram indeferidas pelo Poder Judiciário (PERINI, 2003; GONÇALVES, 2017), sobretudo, após a vigência da Lei n 13.021, de 8 de agosto de 2014, que estabeleceu que:

Art. $5^{\circ}$ - No âmbito da assistência farmacêutica, as farmácias de qualquer natureza requerem, obrigatoriamente, para seu funcionamento, a responsabilidade e a assistência técnica de farmacêutico habilitado na forma da lei.

No presente, o ensino técnico em saúde no Brasil possui um caráter privado quando comparamos a distribuição com o setor público. Em 2011, em levantamento realizado na base de dados do Cadastro Nacional de Cursos de Educação Profissional de Nível Técnico (Instituto Nacional de Pesquisas Educacionais Anísio Teixeira), do total de cursos cadastrados (2.991) “[...] no país, 11,94\% eram do setor público e 88,06\%, do setor privado" (PRONKO et al., 2011, p. 107). Ainda nesse estudo, foi observado que havia o cadastro de 124 (4,15\%) cursos de habilitação na subárea Farmácia. Quanto à distribuição segundo dependência administrativa, 2,80\% eram públicos e 4,33\%, privados. Por região, a distribuição foi $1,61 \%$ no Norte; $7,26 \%$, Nordeste; $79,84 \%$, Sudeste; 8,87\%, Sul e 2,42\%, Centro-Oeste (PRONKO et al., 2011). No entanto, por inúmeras razões, entre as quais a expressiva e contínua expansão da rede EPT, há de se considerar que possivelmente ocorreram mudanças nessas distribuições.

Assim sendo, diante do que foi apresentado, percebemos a necessidade de uma legislação, que seja mais consistente e alinhada à atual política pública de saúde 
brasileira, regulamentando a inscrição desses profissionais técnicos em quadros distintos, para a efetiva qualificação da assistência farmacêutica no país.

\section{A EDUCAÇÃO PROFISSIONAL TÉCNICA EM FARMÁCIA}

A expansão da Educação Profissional e Tecnológica (EPT) culminou na oferta e na criação de inúmeros cursos, entre os quais o Curso de Nível Médio em Técnico em Farmácia. Essa conjuntura tem contribuído para a capacitação profissional para a atuação no segmento farmacêutico em especial, para a dispensação do medicamento (BEZZEGH; GOLDENBERG, 2011; GRECO, 2009; STEPHANELLI, 2015).

À luz das palavras do Ministério da Educação (MEC), por intermédio do Catálogo Nacional de Cursos Técnicos (CNCT), o Técnico em Farmácia é o profissional de Farmácia de nível médio que

[...] realiza operações farmacotécnicas. Identifica e classifica produtos e formas farmacêuticas, composição e técnica de preparação. Manipula formas farmacêuticas alopáticas, fitoterápicas, homeopáticas e de cosméticos. Realiza testes de controle da qualidade. Executa, como auxiliar, as rotinas de compra, armazenamento e dispensação de produtos. Realiza o controle e manutenção do estoque de produtos e matérias-primas farmacêuticas, sob supervisão do Farmacêutico. Atende as prescrições médicas dos medicamentos e identifica as diversas vias de administração. Orienta sobre o uso correto e a conservação dos medicamentos (BRASIL, 2016, p. 23).

No entanto, majoritariamente a farmácia — assistência farmacêutica — no Brasil está entregue a leigos, indivíduos sem a mínima educação formal; balconistas e "práticos" que possuem condutas questionáveis do ponto de vista técnico, científico e ético (CORRER; OTUKI, 2013).

A farmácia comunitária é, antes de tudo, um estabelecimento de saúde. Sua principal função é a dispensação de medicamentos que possuem um caráter dual, pois, dependendo da forma como é usado, pode ocasionar efeito positivo ou negativo no paciente (BASTOS; COSTA; CASTRO, 2011). Diante disso, é indiscutível que a oferta de um serviço de qualidade é primordial para a promoção do uso racional de medicamentos (CORRER, OTUKI, 2013). 
Não obstante, o Conselho Federal de Farmácia (CFF), de maneira arbitrária, guiado por interesses de classe, ignora a existência dos demais profissionais (com e sem educação formal de nível técnico - recursos humanos) que trabalham nas farmácias comunitárias, pois não define uma padronização do quantitativo desses trabalhadores, restringindo a inscrição, a fiscalização e a defesa apenas da classe farmacêutica.

Essa situação se torna ainda mais complexa se atentarmos para o fato de que o curso Técnico em Farmácia no Brasil tem sua execução regulamentada pelo MEC e consta no Catálogo Nacional de Cursos Técnicos (CNCT), indo além ao ter a profissão — ocupação "Técnico em Farmácia” - recepcionada pelo Ministério do Trabalho e Emprego (MTE) por meio da Classificação Brasileira de Ocupações (CBO) (BRASIL, 2016; BRASIL, 2019).

Tal desinteresse por parte do CFF denuncia certo distanciamento condenável da discussão em torno da importância da formação profissional técnica em saúde dos trabalhadores de nível médio inseridos nos serviços de saúde no Brasil, com precária qualificação e reconhecimento profissional, pauta que vem sendo discutida desde o movimento da Reforma Sanitária Brasileira, cujos desdobramentos estão presentes no texto da Carta Política Pátria do Brasil (PRONKO et al., 2011).

Felizmente, mesmo existindo desinteresse, desdém e inércia por parte do CFF, encontra-se no Poder Legislativo, na Câmara dos Deputados, tramitando em caráter conclusivo, o Projeto de Lei $\mathrm{n}^{\circ}$ 668/2011, que visa regulamentar o exercício da profissão do Técnico em Farmácia (BRASIL, acesso em 11 jul. 2018).

À vista disso, muitos pesquisadores têm defendido que, em diferentes atividades na farmácia, o Farmacêutico carece do auxílio de outros profissionais e a atuação do técnico devidamente habilitado (com educação formal especifica) qualifica a Prática Farmacêutica (MARIN et al., 2003; CORRER, OTUKI, 2013; STEPHANELLI, 2015). Portanto, ao invés de contratar profissionais que não possuem formação formal, os estabelecimentos farmacêuticos, ao compor o seu quantitativo de recursos humanos, deveriam contratar o Técnico em Farmácia. 
A esse respeito, salientamos que o referido curso, para conferir o perfil profissional com as competências e habilidades supramencionadas, deve possuir carga horária mínima de $1200 \mathrm{~h}$ e ter, em seus componentes curriculares, estágios e disciplinas básicas e específicas como anatomia, fisiologia, biologia, química, farmacologia e legislação farmacêutica, entre outras, com aulas teóricas e práticas em laboratórios, para que o egresso de fato disponha de habilidades e competências indispensáveis para atuar nos diversos segmentos da área farmacêutica, executando as atividades pertinentes sob a supervisão do Farmacêutico (PEREIRA, 2009; BRASIL, 2016). Ademais, cito para que fique claro, que o campo de atuação do Técnico em Farmácia no Brasil incluí:

[...] drogarias. Unidades básicas de saúde e Unidades de dispensação do SUS. Farmácias de manipulação. Farmácias homeopáticas. Indústria farmacêutica. Indústria de cosméticos. Farmácias hospitalares. Distribuidoras de medicamentos, insumos e correlatos (BRASIL, 2016, p. 23).

Nos Estados Unidos da América (EUA), nas farmácias do país, apenas o profissional que obteve formação formal em Técnico em Farmácia (Pharmacy Tecnican) é habilitado para o trabalho, sob a supervisão do Farmacêutico. O referido curso também comtempla disciplinas básicas e específicas como no Brasil (JOHNSTON et al., 2009).

No Brasil, em razão do não reconhecimento da profissão técnica por parte do CFF, não é comum encontrar esses profissionais atuando no segmento farmacêutico, pois resta pouco incentivo para permanecer no segmento farmacêutico para aqueles que buscaram se qualificar obtendo educação formal. É uma situação muito diferente da dos EUA, onde apenas o Farmacêutico e o profissional Técnico em Farmácia podem atuar no segmento farmacêutico após certificação em órgão competente (GONÇALVES, 2017). Sobre isso, ao invés de se oporem, os Farmacêuticos e o CFF, em respeito à farmácia, deveriam reconhecer que não há mais espaço para improvisações e atuações amadorísticas na farmácia brasileira (GRECO, 2009).

Nessa linha, mencionamos o que foi evidenciado em estudo conduzido por Gonçalves (2017), em que se observou, após aplicação de um teste, que o indivíduo com educação formal no curso Técnico em Farmácia, cuja duração em média é de 18 
meses (um ano e meio), possui um conhecimento notoriamente maior que os balconistas (sem educação formal), os quais possuem em média 10 a 18 anos de experiência. Logo, a aplicação do teste demonstrou que os balconistas precisam de muitíssimo tempo de experiência para obter um conhecimento muito inferior ao dos Técnicos em Farmácia, que por sua vez é obtido em um ano e meio. Portanto, fica evidente a importância de se investir na educação formal desses profissionais, bem como limitar a atuação de profissionais sem tal formação.

Os avanços na área farmacêutica e nas políticas públicas de saúde têm exigido a qualificação da assistência farmacêutica. Nesse sentido, vê-se a importância do trabalho do Técnico em Farmácia na assistência direta com o paciente, sob a supervisão do Farmacêutico como parte que deveria ser vista como indissociável desse processo (BARROS NETO, 2019).

A formação e a incorporação do Técnico em Farmácia estão imersas em um contexto histórico de oposição concebida por um comportamento corporativista por parte dos Farmacêuticos. Nessa esteira, os concluintes dos cursos de nível técnico optam pela verticalização para curso de graduação em Farmácia que pertence ao itinerário formativo no intuito de obter maior reconhecimento profissional (BARROS NETO, 2019).

O que se pretende não é a equiparação dos direitos e das atribuições do Técnico em Farmácia com os do Farmacêutico, mas a proteção e o direcionamento legal específico quanto às atribuições que são pertinentes ao nível técnico. Porque o profissional Técnico em Farmácia possui especificidades em seus processos de trabalho - em suas ações construídas no cuidado em saúde —; é portador de potencialidades que devem ser reconhecidas pelo profissional Farmacêutico que objetiva a qualificação da assistência farmacêutica.

Essa é a expectativa de todos os discentes, docentes e egressos dos cursos Técnicos em Farmácia, como também de alguns poucos Farmacêuticos, na medida em que saber-se possuidor de direitos é, para o ser humano, algo inestimável e de imenso valor (GONÇALVES FILHO, 1998). 
A partir dessas informações, resta claro que a educação formal é essencial e deveria ser requisito fundamental para atuação de todos os profissionais que queiram atuar nos diversos segmentos da área farmacêutica, cabendo ao CFF contribuir para a legalização da atuação dos técnicos, bem como fiscalizar e exigir tais requisitos, e não ser pedra de tropeço para o avanço do Projeto de Lei supradito.

\section{CONSIDERAÇÕES FINAIS}

Os sonhos possíveis precisam de luta para se tornarem realidade. O direito nos dá o instrumento para que, por meio de constante luta, alimentada pela esperança alcancemos o que sonhamos.

A legalização da profissão Técnica em Farmácia é uma deliberação oportuna e urgente, que exigirá a formação institucional para atuação após inscrição nos Conselhos de Farmácia, pois coopera assim para consolidação e expansão dos Cursos Técnicos de Nível Médio em Farmácia, com a EPT, bem como para a inclusão do pessoal Técnico em Farmácia no segmento farmacêutico e, em especial na Atenção Básica. Ao qualificar o processo de trabalho Farmacêutico e Técnico, bem como a assistência farmacêutica, tal legalização otimiza tempo e recursos, aumentando a produtividade e resolutividade das ações na farmácia, e ressignifica os espaços sociais, tanto no âmbito público quanto no privado. No entanto, é importante que ambos os profissionais - o Técnico e o Farmacêutico - estejam abertos para o trabalho em equipe, integrado e articulado, compartilhando saberes e práticas, como preza o princípio da integralidade.

A revisão apresentada fornece subsídios que contribuem para proposição de políticas direcionadas tanto à EPT quanto ao reconhecimento profissional. Reconhecemos as políticas públicas como um instrumento que operacionaliza as reformas necessárias nas instituições públicas e nas organizações em geral (DIAS; MATOS, 2012). A proposta de uma política pública voltada para a questão deve basearse em ampla análise das potencialidades da educação formal e reconhecimento legal para a qualificação da assistência farmacêutica no Brasil. Portanto, uma política dessa natureza deve ser articulada e condicionada pelas dimensões: econômica, social e educacional. Atrelados a essas dimensões, os objetivos devem se propor: 1) buscar o desenvolvimento econômico e social, por meio da definição, da proteção e do 
direcionamento legal especifico quanto às atribuições pertinentes ao nível técnico, respeitando as especificidades dos processos de trabalho desse profissional, consequentemente permitindo a sua inscrição e sua incorporação em quadro separados nos Conselhos Regionais de Farmácia, bem como exigir a educação formal e o número de inscrição para atuação no mercado de trabalho; 2) diminuir a desigualdade social e facilitar o acesso equitativo ao ensino Técnico em Farmácia; 3) propor, após ampla discussão cívica e democrática, novas Diretrizes Curriculares Nacionais para o curso Técnico em Farmácia, redefinindo os princípios, os fundamentos, as condições e os procedimentos para a formação em nível Técnico em Farmácia, para serem aplicadas, em âmbito nacional, na organização, no desenvolvimento e na avaliação dos projetos pedagógicos do curso em questão, tendo em vista os avanços no campo da deontologia e legislação farmacêutica brasileira; 4) conceber a política pública em questão de forma integrada, sob a ótica dos princípios de universalidade, de cooperação, de integralidade e, sobretudo, de eficácia e eficiência, conferindo equilíbrio político, social e econômico; 5) promover, sob a ótica da saúde, em especial do princípio da integralidade, condições para sensibilização e estabelecimento de vínculos entre os profissionais Técnicos em Farmácia e Farmacêuticos, rompendo disputas históricas e reconhecendo a necessidade de mudança, como via para promoção de um interesse comum: a qualificação da assistência farmacêutica no Brasil.

Nesse sentido, com fundamentos nas lições de Dias e Matos (2012), reconhecemos que o problema público, apresentado neste estudo, por violar compromissos legítimos; por enfraquecer a condição comum desses determinados profissionais; por ir contra os valores alicerçantes das políticas de saúde do país e pelos danos causados aos bens sociais, incide na necessidade de uma política pública que, orientada pelas dimensões e pelos objetivos antes mencionados, resolva todo o problema social e público em questão.

A Farmácia no Brasil reclama mudança, porque mudança é da vida. Compete ao legislativo e ao CFF reconhecê-las e fazê-las com serenidade, segurança e principalmente respeito à Carta Política Pátria do Brasil.

\section{AGRADECIMENTOS}


Os autores agradecem ao Instituto Federal do Espírito Santo, Campus Colatina e à Universidade Presbiteriana Mackenzie.

\section{REFERÊNCIAS}

BARROS NETO, Sebastião Gonçalves de; CYSNEIROS, Roberta Monterazzo; BORGES, Luiz Henrique. Percepção do Farmacêutico sobre sua relação de trabalho com o Técnico em Farmácia: Integralidade no Cuidado a Saúde. In: CONGRESSO DE EDUCAÇÃO PROFISSIONAL E TECNOLÓGICA DO IFSP, 4., 2018, Araraquara. Anais... Araraquara: IFSP, 2018. p. 1-4.

BARROS NETO, Sebastião Gonçalves de. O cuidado farmacêutico no âmbito da atenção básica sob a ótica da integralidade. 2017. 168 f. Dissertação (Mestrado em Políticas Públicas e Desenvolvimento Local) - Escola Superior de Ciências da Santa Casa de Misericórdia de Vitória, Vitória, 2017.

BARROS NETO, Sebastião Gonçalves de. Técnicos em Farmácia: trajetórias formativas de egressos do Curso Técnico de Nível Médio em Farmácia. 2019. 42f. Monografia (Especialização em Educação Profissional e Tecnológica) - Instituto Federal de Educação, Ciência e Tecnologia do Espírito Santo - IFES, Colatina, ES, 2019.

BASTOS, Augusto Amorim; COSTA, Ediná Alves; CASTRO, Lia Lusitana Cardozo de. Trabalho em saúde: vigilância sanitária de farmácias no município de Salvador (Bahia, Brasil). Ciência \& Saúde Coletiva, Rio de Janeiro, v. 16, n. 5, p. 2397-400, 2011.

BEZZEGH, Nadine Judith; GOLDENBERG, Paulete. The challenge of responsible dispensing: formal education versus professional practice. Brazilian Journal of Pharmaceutical Sciences, v. 47, n. 1, p. 63-3, 2011.

BRASIL. Câmara dos Deputados. PL 668/2011. Regulamenta o exercício da profissão do Auxiliar de Farmácias e Drogarias. Disponível em:

<http://www.camara.gov.br/proposicoesWeb/fichadetramitacao?idProposicao=4943 $>$ Ac esso em: 11 jul. 2018.

BRASIL. Lei de 3 de outubro de 1832. Dá nova organização ás actuaes Academias Medico-cirurgicas das cidades do Rio de Janeiro, e Bahia. Disponível em: <http://www2.camara.leg.br/legin/fed/lei_sn/1824-1899/lei-37274-3-outubro-1832563716-publicacaooriginal-87775-pl.html>. Acesso: 20 out. 2018.

BRASIL. Lei $\mathrm{n}^{\circ}$ 5.648, de 11 de dezembro de 1970. Cria o Instituto Nacional da Propriedade Industrial e dá outras providências. Diário Oficial da União, 1970. Disponível em: 〈http://www.planalto.gov.br/ccivil_03/leis/L5648.htm>. Acesso em: 20 out. 2018. 
BRASIL. Lei n ${ }^{\circ} 13.021$, de 8 de agosto de 2014. Dispõe sobre o exercício e a fiscalização das atividades farmacêuticas. Diário Oficial da União, Brasília, 11 ago. 2014. Disponível em: 〈http://www.planalto.gov.br/ccivil_03/_Ato20112014/2014/Lei/L13021.htm>. Acesso em: 13 out. 2018.

BRASIL. Lei no 5.991, de 17 de dezembro de 1973. Dispõe sobre o Controle Sanitário do Comércio de Drogas, Medicamentos, Insumos Farmacêuticos e Correlatos, e dá outras Providências. Brasília, 1973. Disponível em: <http://www.planalto.gov.br/ccivil_03/LEIS/L5991.htm>. Acesso em: 5 dez. 2018.

BRASIL. Lei no 3.820, de 11 de novembro de 1960. Cria o Conselho Federal e os Conselhos Regionais de Farmácia e dá outras providências. Diário Oficial da União. Brasília, 1960.

BRASIL. Ministério da Educação. Catálogo Nacional de Cursos Técnicos. Brasília, 2009a.

BRASIL. Ministério da Educação. Catálogo Nacional de Cursos Técnicos. 3. ed. Brasília, 2016.

BRASIL. Ministério da Saúde. Diretrizes para estruturação de farmácias no âmbito do Sistema Único de Saúde. Brasília, 2009b. Disponível em: <http://www.planalto.gov.br/ccivil_03/leis/L3820.htm >. Acesso em: 7 jun. 2017.

BRASIL. Ministério do Trabalho. Classificação Brasileira de Ocupações <http://www.mtecbo.gov.br/cbosite/pages/pesquisas/ResultadoOcupacaoMovimentacao .jsf >. Acesso em: 07 de mar. 2019.

CONSELHO FEDERAL DE FARMÁCIA (Brasil). Nota Técnica: perguntas e respostas referentes às Resoluções do CFF n ${ }^{\circ} 585$ e n n 586, de 29 de agosto de 2013. Brasília, 2013.

CORRAL, Florentina Santos Diez Del; SOUZA, Mirabeau Levi Alves de; NEGRÃO, Odulia Leboreiro. Do boticário ao farmacêutico: o ensino de farmácia na Bahia de 1815 a 1949. Salvador: EDUFBA, 2009.

CORRER, Cassyano Januário; OTUKI, Michel Fleith (Org.). A prática farmacêutica na farmácia comunitária. Porto Alegre: Artmed, 2013.

CORRER, Cassyano Januário; PONTAROLO, Roberto; RIBEIRO, Alyne Simon de Carvalho. A farmácia comunitária no Brasil. In: CORRER, Cassyano Januário; OTUKI, Michel Fleith (Org.). A prática farmacêutica na farmácia comunitária. Porto Alegre: Artmed, 2013. p. 3-26.

DIAS, Reinaldo; MATOS, Fernanda. Políticas públicas: princípios, propósitos e processos. São Paulo: Atlas, 2012.

EDLER, Flavio Coelho. Boticas \& Pharmacias: uma história ilustrada da farmácia no Brasil. Rio de Janeiro: Casa da Palavra, 2006. 
GONÇALVES, Ana Maria Rosa Freato. A importância da educação formal para a dispensação de medicamentos: um estudo transversal. 2017. 177 f. Dissertação (Mestrado em Ciências Farmacêuticas) - Faculdade de Ciências Farmacêuticas, Universidade de São Paulo, Ribeirão Preto, 2017.

GONÇALVES FILHO, José Moura, Humilhação social: um problema político em psicologia. Psicologia USP, São Paulo, v. 9, n. 2, p.11-67, 1998.

GRECO, Maria Cecília Machado. O curso técnico em farmácia na ETSUS-SP: contribuições para o debate. 2009. 137 f. Dissertação (Mestrado Profissional em Gestão do Trabalho e da Educação na Saúde) - Escola Nacional de Saúde Pública Sergio Arouca, Rio de Janeiro, 2009.

JOHNSTON, Mike et al. The pharmacy technician foundations and practies. Upper saddle river: New Jersey, 2009.

MARIN, Nelly et. al (Org.). Assistência farmacêutica para gerentes municipais. Rio de Janeiro: OPAS/OMS, 2003.

MELO, Daniela Oliveira de et al. Capacitação e intervenções de técnicos de farmácia na dispensação de medicamentos em Atenção Primária à Saúde. Ciência \& Saúde

Coletiva, Rio de Janeiro, v. 22, n. 1, p. 261-8, 2017.

MERHY, Emerson Elias. Saúde: a cartografia do trabalho vivo em ato. São Paulo: Editora Hucitec, 2002.

NAVES, Janeth de Oliveira Silva; MERCHAN-HAMANN, Edgar; SILVER, Lynn Dee. Orientação farmacêutica para DST: uma proposta de sistematização. Ciência \& Saúde Coletiva, Rio de Janeiro, v. 10, p. 1005-14, 2005.

PEREIRA, Sandra. Profissão técnico em Farmácia. Revista Poli Saúde educação trabalho, v. 1, n. 5, p. 22-3, maio/jun., 2009.

PERINI. Edson. Assistência farmacêutica: fundamentos teóricos e conceituais. In: ACURCIO, Francisco de Assis. Medicamentos e Assistência farmacêutica. Belo Horizonte: Coopmed, 2003.

PRONKO, Marcela et al. A formação de trabalhadores técnicos em saúde no Brasil e no Mercosul. Rio de Janeiro: EPSJV, 2011.

SANTOS, Manoel Roberto da Cruz. Profissão farmacêutica no Brasil: história, ideologia e ensino. Ribeirão Preto: Ed. Holos, 1999.

STEPHANELLI, Lásaro Linhares. Técnicos em farmácia em atividades de assistência farmacêutica na atenção básica à saúde do Sistema Único de Saúde: formas de inserção e participação. 2015. 94 f. Dissertação (Mestrado Profissional em 
Educação Profissional em Saúde) - Escola Politécnica de Saúde Joaquim Venâncio, Fundação Oswaldo Cruz, Rio de Janeiro, 2015.

VELLOSO, Verônica Pimenta. Farmácia na Corte Imperial (1851 - 1887): práticas e saberes. 2007. 345 f. Tese (Doutorado em História das Ciências em Saúde) - Fundação Oswaldo Cruz, Rio de Janeiro, 2007. 